\title{
References
}

Bascomb, C. L., 1964. Rapid method for the determination of cation exchange capacity of calcareous and non-calcareous soils. Journal of the Science of Food and Agriculture 12: 821-823.

Van den Born, G. J. \& P. Buurman, 1985. Soil information on mafic rocks of north Galicia, Spain. 1. Soil genesis and classification. Netherlands Journal of Agricultural Sciences 33: 62-64.

This synopsis is based on Chapter 7 of the report 'Weathering and soil formation on mafic und ultramafic rocks in N Galicia, Spain' by G. J. van den Born, A. K. Bregt, H. Kok \& J. Zijlstra (editors: P. Buurman \& E. L. Meijer). Research Project J050816 report 1981, 2nd ed. Dept. of Soil Science and Geology, Agricultural University, Wageningen 1985. 193 pp., 32 figs., 24 tables, refs., 12 appendices. Available as paper copy (order R030P, $f 30$ including postage) or on microfiche (order R030M, $f$ 17,50 including postage) at: NARD, clo Pudoc, P.O. Box 4, 6700 AA Wageningen, Netherlands (telex 45015 blhwg $n l$.)

\section{Heterogeneity of Dutch rainfall}

J. V. Witter (Department of Hydraulics and Catchment Hydrology and Department of Mathematics, Agricultural University, Wageningen, Netherlands)

Received 16 January 1985; accepted 19 February 1985

Abstract. Rainfall data for the Netherlands have been used to investigate aspects of heterogeneity of rainfall, in particular local differences in rainfall levels, time trends in rainfall, and local differences in rainfall trend. The possible effect of urbanization and industrialization on the distribution of rainfall has also been studied. Consideration has been given to whether local differences in rainfall justify a partition of the Netherlands into regions. Finally, the degree of areal reduction in hydrological design based on variation of rąinfall in time and space has been investigated. Key-words: rainfall, trend, local differences, urban precipitation enhancement, kriging, areal reduction factor.

Trends in rainfall. The rainfall characteristics used in the investigation of homogeneity in time and space are total annual rainfall and annual frequencies of exceedance during the summer or the winter period of certain threshold values $(1,15$ and $25 \mathrm{~mm}$ ) of daily rainfall. Time trends in these rainfall characteristics averaged over the Netherlands have been estimated. For the period 1951-1979, the time trend is negative for the summer period; for the period 1906-1979, the time trend is posi- 
tive for the winter period. Time trends in rainfall series were found to be related to the occurrence of circulation types.

Local differences in rainfall. Local differences in the rainfall characteristics mentioned above have been investigated by using the kriging method (Matheron, 1971) that gives the best linear unbiased predictor of such differences. As may be expected, there are local differences, both in rainfall level and in time trends in the rainfall series with respect to the annual mean. Many of the rainfall series investigated exhibit inhomogeneities. Two possible causes of these inhomogeneities are changes in the frequency of occurrence of circulation types and anthropogenic activities, such as urbanization and industrialization.

A possible partition of the Netherlands into regions has been investigated by using rainfall data for the period 1951-1979. Partitions into regions are not satisfactory for rainfall trends: both the geographical distribution of trends and the degree of trend in some long-term rainfall records are not in agreement with a partition based on rainfall trends over the shorter period 1951-1979. With regard to rainfall level it suffices to assume that the design rainfall at a given location is proportional to the mean summer or winter rainfall. Therefore, a partition of the Netherlands into regions is not necessary. This is in agreement with suggestions by Buishand \& Velds (1980).

Urban precipitation enhancement. The influence of urbanization and industrialization on precipitation (urban effects) has been investigated by using the method of Lowry (1977), which allows for changes in frequency of occurrence of circulation types.

Changes in mean daily rainfall for 32 rainfall stations between the industrialized and urbanized period (1956-1979) and the non-industrialized period (1932-1955), with a stratification of days according to season and type of large-scale weather pattern ('Grosswettertypen'), have been investigated. Although the results were sometimes inconclusive and not always in accordance with the hypothesis of an urban effect, there are indications of urban effects for the zonal circulation type and for three of the meridional circulation types.

Moderate rainfalls were also found to be affected, and urban effects in the summer period increase with rainfall depth.

Areal reduction factor. Methods to estimate the statistical areal reduction factor (ARF) can be based on annual maxima series of both point and areal rainfall (USWB, 1957-1960; NERC, 1975); on partial duration series of both point and areal rainfall (Bell, 1976); and on the marginal distribution of point rainfall and the correlation-distance function (Rodríguez-Iturbe \& Mejía, 1974; Buishand, 1977). All these estimators were found to produce similar values of the areal reduction factor for daily rainfall $\left(\mathrm{ARF}_{24}\right)$ for three areas each of about $1000 \mathrm{~km}^{2}$ in the Netherlands. These estimates of $\mathrm{ARF}_{24}$ are somewhat lower than those of USWB (1957-1960) for the USA and those of NERC (1975) for Britain, and they are in 
reasonable agreement with earlier estimates of $\mathrm{ARF}_{24}$ for the Netherlands. $\mathrm{ARF}_{24}$ depends strongly on season and on return period.

For small areas, $\mathrm{ARF}_{24}$ is underestimated by the method which uses the marginal distribution of point rainfall and the fitted correlation-distance function. This is due to the large discontinuity at the origin of the fitted linear correlation-distance function:

$$
r(\mathrm{~h})=\varrho_{0}+\theta \mathrm{h}
$$

where

$r(\mathrm{~h})$ is the correlation coefficient at distance $\mathrm{h}$ $\varrho_{0}, \theta$ are parameters.

A mixture of two exponential functions:

$$
r(\mathrm{~h})=\varrho_{0} \exp \left(-\theta_{1} \mathrm{~h}\right)+\left(1-\varrho_{0}\right) \exp \left(-\theta_{2} \mathrm{~h}\right)
$$

does not provide a substantially better fit to the estimated correlation coefficients, but is continuous at the origin and, consequently, leads to higher $\mathrm{ARF}_{24}$ estimates for small areas, although they remain lower than the $A \mathrm{RF}_{24}$ estimates for summer daily rainfalls in the Netherlands in excess of $40 \mathrm{~mm}$ in Kraijenhoff (1963).

The estimates of ARF for hourly rainfall $\left(A R F_{1}\right)$ for the Netherlands are somewhat lower than those given by USWB (1957-1960) and NERC (1975), probably because few hourly rainfall data were available for this study. Especially the correlation-distance function for hourly rainfalls could not be estimated very satisfactorily.

To estimate daily areal rainfall, use has been made of the IRF-0 kriging theory (so assuming that there is no spatial trend) and semi-variograms have been estimated by the multi-realization approach. Contrary to what had been expected, in a substantial number of cases the estimated order of the intrinsic random function differs from zero. Further research is needed on the structure identification, both on the statistical aspects (estimation of the order $\mathrm{k}$ of the intrinsic random function and of the coefficients of the generalized covariance model) and on the physical aspects (semi-variogram or generalized covariance model to be expected under certain assumptions regarding rainfall). Also the kriging predictor of areal rainfall has been compared with the more commonly used arithmetic mean and Thiessen predictor. All three predictors yield similar results, but the kriging predictor is more efficient.

\section{References}

Bell, F. C., 1976. The areal reduction factor in rainfall frequency estimation. Report 35 . Institute of Hydrology, Wallingford.

Buishand, T. A., 1977. De variantie van de gebiedsneerslag als functie van puntneerslagen en hun onderlinge samenhang. (The variance of the amount of rainfall on an area related to point rainfall amounts.) Communications Agricultural University 77-10. Veenman, Wageningen. 
Buishand, T. A. \& C. A. Velds, 1980. Neerslag en verdamping. Royal Dutch Meteorological Institute, De Bilt.

Kraijenhoff, D. A., 1963. Areal distribution of extreme summer rainfall in the Netherlands. Mimeograph, Department of Hydraulics and Catchment Hydrology, Agricultural University, Wageningen.

Lowry, W. P., 1977. Empirical estimation of urban effects on climate: a problem analysis. Journal of Applied Meteorology 16: 129-135.

Matheron, G., 1971. The theory of regionalized variables and its applications. Ecole Nationale Supérieure des Mines de Paris, Paris.

NERC, 1975. Flood studies report, 5 vols. Natural Environment Research Council, London.

Rodríguez-Iturbe, I. \& J. M. Mejía, 1974. On the transformation of point rainfall to areal rainfall. Water Resources Research 10: 729-736.

USWB, 1957-1960. Rainfall intensity-frequency regime, 5 vols. US Department of Commerce, Washington, D.C.

This synopsis is based on a doctoral thesis, Agricultural University, Wageningen, 1984. ix +204 pp., 56 figs., 36 tables, 113 refs., appendices.

Available as paper copy (order R031P, $f 40$ including postage) or on microfiches (order R031M, f22.50 including postage) at: NARD, clo Pudoc, P.O. Box 4, 6700 AA Wageningen, Netherlands (telex 45015 blhwg $\mathrm{nl}$ ).

\title{
Impact of medium-sized wind turbines on birds: a survey on flight behaviour, victims, and disturbance
}

J. E. Winkelman (Research Institute for Nature Management, P.O. Box 9201, 6800 HB Arnhem, Netherlands)

Received 25 January 1985; accepted 27 February 1985

\begin{abstract}
In the autumn and winter of 1983/1984, a study was made on the possible danger of medium-sized wind turbines (tower height 10-30 m, rotor diameter 7-25 m, power $50-300 \mathrm{~kW}$ ) to birds. The main points studied were flight behaviour of birds approaching turbines in daylight, and number of birds killed at night. Some attention was paid to possible loss of breeding and feeding habitat around present sites of turbines.

Key-words: birds, wind turbine, flight behaviour, collision, ecological disturbance, bird mortality.
\end{abstract}

Introduction. Although wind power exploited by wind turbines is thought to be rather harmless to the environment, a possible danger could be the impact on birds (Avery et al., 1976; Bleijenberg \& Feenstra, 1982; Karlsson, 1977). Little has yet been published to support this opinion. So the Dutch National Development Pro- 